\title{
Model and Algorithms of Enterprise Informatization Software Selection Based on Grey Relational Analysis
}

\author{
Hua Shang \\ Modern Educational Technology Center, Civil Aviation Flight University of China, Guanghan 618307, China
}

Corresponding Author Email: shanghua@cafuc.edu.cn

https://doi.org/10.18280/isi.250114

Received: 5 July 2019

Accepted: 12 November 2019

\section{Keywords:}

enterprise informatization, software selection, grey relational analysis (GRA), model and algorithm, decision and optimization

\begin{abstract}
Informatization level is an important criterion for the intellectualization of modern enterprises, and enterprise informatization software is a key part of the implementation of enterprise informatization. In this selection process, there exist the problems such as multifactor constraint, ambiguity, and low distinguishing ability etc. To solve these problems, the author attempted to explore the model and algorithm of enterprise informatization software selection based on the grey relational analysis (GRA). First, the decision indicators were defined and then weighted using the fuzzy decision analysis method. Secondly, in view of the uncertainty of decision analysis in the software selection of enterprise informatization, the GRA was proposed to establish the calculation model of grey correlation degree, and the basic framework and algorithm were also given. Finally, the model and algorithms proposed were verified through case analysis. The research findings provide a theoretical support for the fuzzy decision analysis of complex system, and also have signification application value to the fuzzy decision and evaluation issues in complex system engineering.
\end{abstract}

\section{INTRODUCTION}

The development of modern enterprises is closely related to the level of enterprise informatization. The efficient design and utilization of enterprise informatization software is an important guarantee for improving the level of enterprise informatization $[1,2]$. The enterprise informatization software system is one of the important links for the development of the entire enterprise. With the rapid development of modern information technology, the selection and development of enterprise intelligent software systems have gradually become a research hotspot [3-5]. Especially the implementation of Enterprise Resource Planning (ERP) [6, 7] and Product Data Management (PDM) [8, 9] have also posed higher requirements for enterprise informatization software. For this, a well-operated enterprise informatization software will be very conducive to the improvement of the enterprise's operating efficiency and enhance its market competitiveness.

The software selection of enterprise informatization is a complex decision analysis process, due to the constraints of multiple factors. At present, the research on the selection of enterprise informatization software can be roughly divided into three aspects: the influencing factors; the evaluation and decision indicators; the evaluation and decision model and algorithm of software selection. For instance, Zong and Wang [10] summarized the quality of software systems based on neural networks, and analyzed the evaluation contents of software quality such as attributes selection, target determination, model establishment, and neural network learning. According to the requirements of aerospace software quality management, Mei et al. discussed the selection of aerospace software system based on test process management [11]. Adewumi et al. [12] reviewed and analyzed the quality evaluation model of open source software systems in order to examine the characteristics, unique advantages and limitations of the existing open source quality model. Washizaki [13] explored common pitfalls and countermeasures in software quality measurement and evaluation, and analyzed uncertainty prediction, machine learning-based algorithms, and evaluation of standards and models. From the perspective of user needs, Yue and Zhang [14] proposed a software quality evaluation model based on group decision making and projection measures. Wu et al. [15] established a software project performance evaluation system and provided a fuzzy evaluation model for software project performance based on grey cluster analysis. However, following the development of computer science and the progress of the society, the demand model for enterprise informationization has been constantly improved, and the related software systems also vary. Therefore, the influencing factors and decision indicators of software selection should be changed. Meanwhile, because of the inevitable existence of uncertainty factors in the process of software selection, it is essentially a fuzzy decision analysis process. Grey relational analysis, with a good application effect on dealing with fuzzy uncertainty problems, has been widely used in engineering [16-19], and achieved good application results. But it needs to be further studied on how to effectively transform the grey correlation coefficients to proximity of fuzzy decision in complex systems. In view of the above, this paper conducts a targeted analysis for the software selection of enterprise informatization based on the grey system theory [20-23]. It also deeply analyzes the key contents of the multi-attribute decision analysis such as index selection, weight generation, algorithm implementation etc. Finally, a selection model of enterprise informatization software based on GRA was established. 
The paper consists of five parts. The first part performs the decision analysis for the selection of enterprise informatization software, and introduces the related developments and existing deficiencies; the second part expounds on the decision indicators for software selection; the third part discusses the weights of AHP-based software decision indicators; the fourth part gives an in-depth discussion on the generation of the software selection model, and the algorithms; the fifth part compares and analyzes the model and algorithms of enterprise informatization software selection based on grey relational analysis, and then gives the relevant analysis results; the last part is the conclusion.

\section{ESTABLISHING DECISION INDICATORS FOR SOFTWARE SELECTION}

The software selection of an enterprise is generally made by comprehensively considering its influencing factors such as enterprises' own development needs, informatization software development, and software developers or service providers. Especially with the mature development of network technology and information technology, it's more necessary to include various factors.

\subsection{The enterprise's own development needs $A_{1}$}

(1) Basic informatization conditions for $A_{11}$

The development of informatization software systems requires the hardware facilities and soft power of enterprises. It also involves the production mode, organizational structure, and personnel quality of the enterprise.

(2) Management ability and level $A_{12}$

A good environment, and supporting high-efficiency information management technology levels and abilities are necessary.

(3) Functional requirements and goals $A_{13}$

The development of informatization software system should combined with the actual situation of the enterprise in terms of production, operation, management, and sales, and also integrates its mid-to-long-term and short-term development plans and goals.

\subsection{Information software system development $A_{2}$}

(1) Adaptability $A_{21}$

It should be considered in two aspects: the integration and good secondary development performance of software system; its ability to adapt to different platforms.

(2) Operability $A_{22}$

It mainly refers to whether the software system is convenient for use by different levels of designers, managers, etc., and whether it is convenient for the implementation of work processes and efficiency.

(3) Functionality $A_{23}$

The development of informatization software system needs to consider: the aspects of enterprise information management to be satisfied; the way to implement the enterprise information management function; the degree of enterprise information management, that is, the degree of achievement.

(4) Integration $A_{24}$

It needs to be considered in two aspects: one is the completeness of the software system to meet the needs of the enterprise informatization, and the other is the integration degree of software system functions, that is, the seamless integration of interfaces, and applications, etc.

(5) Upgradability $A_{25}$

It is mainly the ability to upgrade software systems, especially the implantability and integration of new technologies and functions.

(6) Reliability and safety $A_{26}$

It mainly means the possibility that the software system does not fail, and the function crashes, as well as the ability that the software system is not maliciously modified, destroyed, and leaked.

\subsection{Software developers or service providers $A_{3}$}

(1) Development cycle $A_{31}$

Software developers or service providers should be capable of controlling the software system's R\&D, upgrades, and services in accordance with the development needs of the enterprise.

(2) Economy $A_{32}$

The design, development, maintenance, and repair costs of the software system should be consistent with the budget range of the enterprise.

(3) Maintenance and service capabilities $A_{31}$

It refers to the follow-up software system maintenance and service work provided by software developers or service providers.

\section{WEIGHTING THE DECISION INDICATORS FOR SOFTWARE SELECTION}

The weight of decision indicators for software selection essentially means the importance of different decision indicators in software selection, that is, the ability to contribute to decision-making results. Considering that the decisionmaking process of software selection is based more on qualitative decision information, this paper chooses the AHP method that is more systematic, based on less quantitative information, and simple and practical, to obtain the weights of decision indicators [24-26].

Assuming that there is a total of $K$ decision indicators $A$ at a certain layer, the decision matrix at this layer is obtained using a 1-9 scale method:

$$
D=\left[\begin{array}{cccc}
d_{11} & d_{12} & \cdots & d_{1 K} \\
d_{21} & d_{22} & \cdots & d_{2 K} \\
\vdots & \vdots & \vdots & \vdots \\
d_{K 1} & d_{K 2} & \cdots & d_{K K}
\end{array}\right]
$$

And, the decision matrix has the following characteristics:

$$
d_{i j} \mid i, j \leq K\left(\begin{array}{l}
>0(i \neq j) \\
=1(i=j) \\
=1 / d_{j i}
\end{array}\right.
$$

Normalize the decision matrix $D$ :

$$
\bar{w}_{i j}=d_{i j} / \sum_{i=1}^{K} d_{i j}
$$


Then, the relative weight value $w_{i j}$ is given as:

$$
w_{i j}=\sum_{j=1}^{K} \bar{w}_{i j} / \sum_{i=1}^{K} \sum_{j=1}^{K} \bar{w}_{i j}
$$

Perform the consistency check of the decision matrix $D$ :

$$
\begin{aligned}
C I=\frac{\lambda_{\max }-K}{K-1} & =\frac{\frac{1}{K} \sum_{i=1}^{K} \frac{(D w)_{i}}{w_{i}}-K}{K-1} \\
C R & =C I / R I
\end{aligned}
$$

At $C R<0.1$, it indicates that the consistency of the decision matrix is acceptable; otherwise, the judgment matrix needs to be reset.

Therefore, the above method was used to obtain a decision matrix $D_{A}$ of the criterion layer, and also the corresponding weight sequence $W_{A}$ :

$$
\begin{aligned}
& D_{A}=\left[\begin{array}{ccc}
1 & \frac{2}{3} & 2 \\
\frac{3}{2} & 1 & 3 \\
\frac{1}{2} & \frac{1}{3} & 1
\end{array}\right] \\
& W_{A}=\left\{w_{A 1}, w_{A 2}, w_{A 3}\right\}=\{0.333,0.500,0.167\}
\end{aligned}
$$

The decision matrix of the decision indicator at each criterion layer should be obtained first:

$$
\begin{gathered}
D_{A_{1}}=\left[\begin{array}{ccc}
1 & 2 & \frac{2}{3} \\
\frac{1}{2} & 1 & \frac{1}{3} \\
\frac{3}{2} & 3 & 1
\end{array}\right] \\
D_{A_{2}}=\left[\begin{array}{llllll}
1 & \frac{1}{2} & \frac{1}{3} & \frac{1}{3} & \frac{1}{2} & \frac{1}{3} \\
2 & 1 & \frac{2}{3} & 1 & 2 & \frac{1}{2} \\
3 & \frac{3}{2} & 1 & 2 & 3 & 1 \\
3 & 1 & \frac{1}{2} & 1 & 2 & \frac{2}{3} \\
2 & \frac{1}{2} & \frac{1}{3} & \frac{1}{2} & 1 & \frac{1}{2} \\
3 & 2 & 1 & \frac{3}{2} & 2 & 1
\end{array}\right] \\
D_{A_{3}}=\left[\begin{array}{llll}
1 & \frac{1}{2} & \frac{1}{3} \\
2 & 1 & \frac{2}{3} \\
3 & \frac{3}{2} & 1
\end{array}\right]
\end{gathered}
$$

Next, the weight sequences of the corresponding decision indicators are derived as:

$$
\begin{gathered}
W_{1}=\left\{w_{11}, w_{12}, w_{13}\right\}=\{0.333,0.167,0.500\} \\
W_{2}=\left\{w_{21}, w_{22}, w_{23}, w_{24}, w_{25}, w_{26}, w_{27}\right\}=\{0.070,0.158,0.260,0.170,0.100,0.242\} \\
W_{3}=\left\{w_{31}, w_{32}, w_{33}\right\}=\{0.500,0.333,0.167\}
\end{gathered}
$$

\section{THE SOFTWARE SELECTION MODEL AND ALGORITHM BASED ON GRA}

\subsection{Generation of grey sequences in software selection}

The software selection aims to determine the advantages and disadvantages of software, so it is necessary to classify the selected software systems into different levels based on decision indicators, and the decision indicators corresponding to each level form a grey comparison sequence. There were three levels: excellent, good, and general, corresponding to the Level I, II and III, respectively; the interval scale of level I was $[0.90,1.00]$, and the reference scale was taken as 1.0 ; the interval scale of level II was[0.70,0.90], and the reference scale was 0.8 ; the reference scale of level III was 0 . If there are $n$ decision indicators $x$ on the corresponding criterion layer, the relevant grey comparison sequence is:

$$
\left\{\begin{array}{l}
X_{I}=\left\{x_{I 1}, x_{I 2}, \cdots, x_{I n},\right\} \\
X_{I I}=\left\{x_{I I 1}, x_{I I 2}, \cdots, x_{I I n},\right\} \\
X_{I I I}=\left\{x_{I I I 1}, x_{I I I 2}, \cdots, x_{I I I n},\right\}
\end{array}\right.
$$

For the software system to be decided, its corresponding decision indicators form a grey reference sequence $X_{o}$ :

$$
X_{o}=\left\{x_{o 1}, x_{o 2}, \cdots, x_{o n},\right\}
$$

where, $x_{o i} \mid 1 \leq i \leq n$ is the value of the decision indicator corresponding to the software system to be decided.

\subsection{Calculation model for grey correlation in software selection}

Based on the grey reference sequence $X_{o}$ and the grey comparison sequence $X_{p} \mid \mathrm{P}=I, I I, I I I$, we obtained the maximum absolute difference $\Delta d_{i P}^{\max }$ between two levels for the decision indicator $i$ in the software selection:

$$
\Delta d_{i P}^{\max }=\max _{P} \max _{i}\left|x_{o i}-x_{i P}\right|
$$

The minimum absolute difference $\Delta d_{i P}^{\text {min }}$ between the two levels for decision indicators $i$ is given as:

$$
\Delta d_{i P}^{\min }=\min _{P} \min _{i}\left|x_{o i}-x_{i P}\right|
$$

Based on the grey reference sequence $X_{o}$ and grey comparison sequence $X_{p} \mid \mathrm{P}=I, I I, I I I$ for software system selection, we obtained the grey correlation coefficient of decision indicators $i$ :

$$
\xi_{i P}=\frac{\Delta d_{i P}^{\min }+\rho * \Delta d_{i P}^{\max }}{\left|x_{o i}-x_{i P}\right|+\rho * \Delta d_{i P}^{\max }}
$$


where, $\rho$ is the distinguishing coefficient, which is generally taken as $\rho=0.5$.

Given that the weight of the decision indicator $i$ is $w_{i}$, then the grey correlation $\delta_{o P}$ between the grey reference sequence $X_{o}$ and the grey comparison sequence $X_{p} \mid \mathrm{P}=I, I I, I I I$ is given as:

$$
\delta_{o P}=\sum_{i=1}^{n}\left(w_{i} * \xi_{i P}\right)
$$

\subsection{Optimization of grey correlation in software selection}

According to the grey system theory, the GRA is mainly to compare the shape similarity between the grey reference sequence and the grey comparison sequence. But in fact, there is still certain location proximity between them. To ensure more reliable decision-making results, the location of the grey correlation $\delta_{o P}$ was optimized to obtain the location proximity $\lambda_{o P}$. In this paper, Euclidean distance was used as the calculation model to achieve the location optimization of the grey correlation degree $\delta_{o P}$.

$$
\begin{gathered}
d_{o P}=\left(1-\lambda_{o P}\right) * \sqrt{\sum_{i=1}^{n}\left(w_{i} * \xi_{i P}\right)^{2}} \\
\operatorname{st} \min \left\{\varphi\left(\lambda_{o P}\right)\right\}=\min \left(\sum_{j=1}^{N} \sum_{P=1}^{I I I}\left(1-\lambda_{o P}\right)^{2} * \sqrt{\left[\sum_{i=1}^{n}\left(w_{i} * \xi_{i P}\right)^{2}\right]^{2}}\right)
\end{gathered}
$$

Then, the constructor $\psi\left(\lambda_{o P}, \zeta\right)$ is calculated as:

$$
\psi\left(\lambda_{o P}, \zeta\right)=\sum_{P=1}^{I I I}\left(1-\lambda_{o P}\right)^{2} \sum_{i=1}^{n} \sqrt{\left[\sum_{i=1}^{n}\left(w_{i} * \xi_{i P}\right)^{2}\right]^{2}}-\zeta *\left(\sum_{P=1}^{I I I}\left(1-\lambda_{o P}\right)-1\right)
$$

Taking the derivatives of the variables $\lambda_{o P}$ and $\zeta$, we obtained the optimized location proximity $\lambda_{o P}$ in the software selection:

$$
\lambda_{o P}=1-1 / \sum_{Q=1}^{I I I} \sqrt{\left[\frac{\sum_{i=1}^{n}\left(w_{i} * \xi_{i P}\right)^{2}}{\sum_{i=1}^{n}\left(w_{i} * \xi_{i Q}\right)^{2}}\right]^{2}}
$$

\subsection{Algorithm implementation for software selection}

Based on the above, it can be seen that in the software selection process, the large location proximity $\lambda_{o P}$ obtained based on the grey correlation indicates a closer relationship between the grey comparison sequence and the grey reference sequence. Thus, the attribution level of the software system selection can be obtained:

$$
\lambda_{o S} \mid I \leq S \leq I I I=\max \left(\lambda_{o P} \mid I \leq P \leq I I I\right)
$$

Figure 1 shows the basic process of the algorithm implementation in the selection of enterprise informatization software based on the GRA.

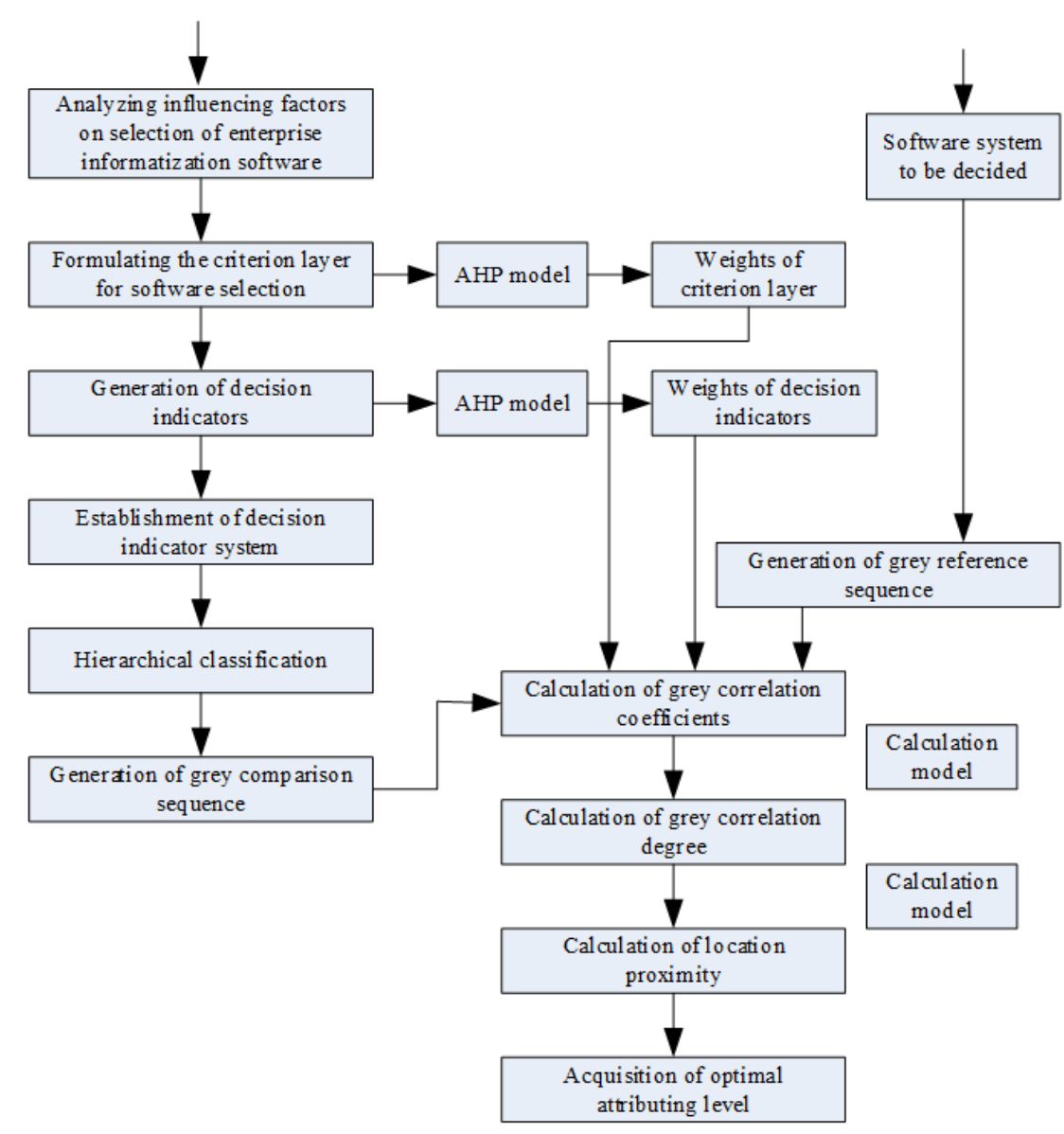

Figure 1. Basic process of the algorithm implementation in the selection of enterprise informatization software 


\section{CASE VERIFICATION AND ANALYSIS}

Taking one steel company and one software development company for case analysis, the steel company has continuously expanded business scope in recent years, leading to a rapid increase in the knowledge and information of production, design, management, and sales, so an information-oriented knowledge management system is urgently needed; this software development company made a bid for this, and obtained the score results of various items after expert review, as shown in Table 1.

Table 1. Review data of the selected software system

\begin{tabular}{|c|c|c|c|c|c|}
\hline $\begin{array}{c}\text { Basic } \\
\text { conditions } \\
A_{11}\end{array}$ & $\begin{array}{c}\text { Management } \\
\text { ability and level } \\
A_{12}\end{array}$ & $\begin{array}{c}\text { Functional } \\
\text { requirements and } \\
\text { goals } A_{13}\end{array}$ & Adaptability $A_{21}$ & Operability $A_{22}$ & Functionality $A_{23}$ \\
\hline 0.90 & 0.80 & 1.00 & 0.80 & 0.90 & 0.90 \\
\hline $\begin{array}{c}\text { Integration } \\
A_{23}\end{array}$ & Upgradability $A_{25}$ & $\begin{array}{c}\text { Reliability and safety } \\
A_{26}\end{array}$ & $\begin{array}{c}\text { Development } \\
\text { cycle } A_{31}\end{array}$ & Economy $A_{32}$ & $\begin{array}{c}\text { Maintenance and } \\
\text { service capacity } \\
A_{31}\end{array}$ \\
\hline 0.60 & 0.80 & 0.80 & 0.60 & 0.90 & 0.90 \\
\hline
\end{tabular}

According to the calculation model, the grey correlation coefficient between the bidding software and the three review levels was obtained, as shown in Table 2.

Table 2. Calculation results of grey correlation coefficients

\begin{tabular}{|c|c|c|c|c|}
\hline $\begin{array}{c}\text { Criterion } \\
\text { layer }\end{array}$ & $\begin{array}{c}\text { Decision } \\
\text { indictor layer }\end{array}$ & \multicolumn{3}{|c|}{ Levels } \\
\cline { 2 - 5 }$A_{1}$ & $A_{11}$ & 0.833 & 0.833 & 0.357 \\
\cline { 2 - 5 } & $A_{12}$ & 0.714 & 1.000 & 0.385 \\
\cline { 2 - 5 } & $A_{13}$ & 1.000 & 0.714 & 0.333 \\
\hline \multirow{4}{*}{$A_{2}$} & $A_{21}$ & 0.692 & 1.000 & 0.360 \\
\cline { 2 - 5 } & $A_{22}$ & 0.818 & 0.818 & 0.333 \\
\cline { 2 - 5 } & $A_{23}$ & 0.818 & 0.818 & 0.333 \\
\cline { 2 - 5 } & $A_{24}$ & 0.529 & 0.692 & 0.429 \\
\cline { 2 - 5 } & $A_{25}$ & 0.692 & 1.000 & 0.360 \\
\cline { 2 - 5 } & $A_{26}$ & 0.692 & 1.000 & 0.360 \\
\hline \multirow{4}{*}{$A_{3}$} & $A_{31}$ & 0.647 & 0.846 & 0.524 \\
\cline { 2 - 5 } & $A_{32}$ & 1.000 & 1.000 & 0.407 \\
\cline { 2 - 5 } & $A_{33}$ & 1.000 & 1.000 & 0.407 \\
\cline { 2 - 5 } & & \multicolumn{2}{|c}{} \\
\cline { 2 - 5 }
\end{tabular}

Similarly, the grey correlation and location proximity between the bidding software system and the three review levels were obtained using their respective calculation models, as shown in Table 3.

Table 3. Calculation results of grey correlation and location proximity

\begin{tabular}{|c|c|c|c|}
\hline & Level I & Level II & Level III \\
\hline Grey correlation & 0.795 & 0.857 & 0.374 \\
\hline Location proximity & 0.843 & 0.865 & 0.292 \\
\hline
\end{tabular}

It can be seen from the data in Table 3 that on the one hand, the decision-making results have better consistency, but they are more in line with the actual situation, that is, the difference between the I level and the II level is not obvious, and the selection software system is between excellent and good level; on the other hand, the distinguishing coefficient of the optimized algorithm is higher, which is more conducive to displaying the bad decision results.

\section{CONCLUSIONS}

This paper first discusses about the problems with enterprise informatization software selection, analyzes the related influencing factors, and then defines the decision indicators for the software selection. Meanwhile, considering the information ambiguity in the selection process, it studies the software selection model based on the GRA, and gives the grey correlation degree and the optimized location proximity model, and also related implementation algorithm for selection of enterprise informatization software. Finally, the case analysis was performed to achieve the simulation results, verifying the model and algorithms.

\section{REFERENCES}

[1] Romero, D., Vernadat, F. (2016). Enterprise information systems state of the art: Past, present and future trends. Computers in Industry, 79: 3-13. http://dx.doi.org/10.1016/j.compind.2016.03.001

[2] Gewehr, B., Gebel-Sauer, B., Schubert, P. (2017). Social network of business objects (SoNBO): An innovative concept for information integration in enterprise systems. Procedia Computer Science, 121: 904-912. http://dx.doi.org/10.1016/j.procs.2017.11.117

[3] González-Rojas, O., Ochoa-Venegas, L. (2017). A decision model and system for planning and adapting the configuration of enterprise information systems. Computers in Industry, 92-93: 161-177. http://dx.doi.org/10.1016/j.compind.2017.08.004

[4] Jallow, A.K., Demian, P., Anumba, C.J., Baldwin, A.N. (2017). An enterprise architecture framework for electronic requirements information management. International Journal of Information Management, 37(5): 455-472.

http://dx.doi.org/10.1016/j.ijinfomgt.2017.04.005

[5] Eroğlu, S., Çakmak, T. (2016). Enterprise information systems within the context of information security: A risk assessment for a health organization in Turkey. Procedia Computer Science, 100: 979-986. http://dx.doi.org/doi: 10.1016/j.procs.2016.09.2621

[6] Chofreh, A.G., Goni, F.A., Klemeš, J.J. (2018). Evaluation of a framework for sustainable enterprise resource planning systems implementation. Journal of Cleaner Production, 190: 778-786. https://doi.org/10.1016/j.jclepro.2018.04.182

[7] Chofreh, A.G., Goni, F.A., Klemeš, J.J. (2018). Sustainable enterprise resource planning systems implementation: A framework development. Journal of 
Cleaner Production, 198: 1345-1354. https://doi.org/10.1016/j.jclepro.2018.07.096

[8] Do, N. (2015). Integration of engineering change objects in product data management databases to support engineering change analysis. Computers in Industry, 73: 69-81. http://dx.doi.org/10.1016/j.compind.2015.08.002

[9] Eck, O., Schaefer, D. (2011). A semantic file system for integrated product data management. Advanced Engineering Informatics, 25(2): 177-184. http://dx.doi.org/10.1016/j.aei.2010.08.005

[10] Zong, P.Y., Wang, Y.C. (2019). Software quality evaluation based on neural network: A systematic literture review. Computer Science, 46(11A): 507-516

[11] Mei, L., Liu, H.F., Dong, W.T. (2019). Aerospace software quality evaluation based on test process management. Journal of Xihua University (Natural $\begin{array}{lll}\text { Science } & \text { Edition), } & \text { 38(6): }\end{array}$ https://doi.org/10.3969/j.issn.1673-159X.06.011

[12] Adewumi, A., Misra, S., Omoregbe, N. (2013). A review of models for evaluating quality in open source software. IERI Procedia, 4: 88-92. http://dx.doi.org/10.1016/j.ieri.2013.11.014

[13] Washizaki, H. (2017). Chapter one: Pitfalls and countermeasures in software quality measurements and evaluations. Advances in Computers, 107: 1-22. http://dx.doi.org/10.1016/bs.adcom.2017.06.003

[14] Yue, C., Zhang, J. (2019). Evaluation model of software quality based on group decision-making and projection measure. Journal of Computer Application, 9: 1-11, 507516. https://doi.org/10.11772/j.issn.10019081.2019060984

[15] Wu, H.Y. (2019). A fuzzy evaluation model of software project performance based on grey cluster analysis. Journal of Southwest China Normal University (Natural Science $\quad$ Edition), $\quad 44(9)$ : 68-75. https://doi.org/10.13718/j.cnki.xsxh.2019.09.011

[16] Shinde, A.B., Pawar, P.M. (2017). Multi-objective optimization of surface textured journal bearing by Taguchi based Grey relational analysis. Tribology International, 114: 349-357. https://doi.org/10.1016/j.triboint.2017.04.041

[17] Kadier, A., Abdeshahian, P., Simayi, Y., Ismail, M., Hamid, A.A., Kalil, M.S. (2015). Grey relational analysis for comparative assessment of different cathode materials in microbial electrolysis cells. Energy, 90:
1556-1562.

http://dx.doi.org/10.1016/j.energy.2015.06.108

[18] Pahange, H., Abolbashari, M.H. (2016). Mass and performance optimization of an airplane wing leading edge structure against bird strike using Taguchi-based grey relational analysis. Chinese Journal of Aeronautics, 29: 934-944. http://dx.doi.org/10.1016/j.cja.2016.06.008

[19] Javed, S.A., Mahmoudi, A., Khan, A.M., Javed, S., Liu, S.F. (2018). A critical review: Shape optimization of welded plate heat exchangers based on grey correlation theory. Applied Thermal Engineering, 144: 593-599. https://doi.org/10.1016/j.applthermaleng.2018.08.086

[20] René S.H., Becker, U., Manz, H. (2016). Grey systems theory time series prediction applied to road traffic safety in Germany. IFAC-Papers On Line, 49(3): 231-236. https://doi.org/10.1016/j.ifacol.2016.07.039

[21] Hu, L.Q., He, C.F., Cai, Z.Q., Wen, L., Ren, T. (2019). Track circuit fault prediction method based on grey theory and expert system. Journal of Visual Communication and Image Representation, 58: 37-45. https://doi.org/10.1016/j.jvcir.2018.10.024

[22] Bezuglov, A., Comert, G. (2016). Short-term freeway traffic parameter prediction: Application of grey system theory models. Expert Systems with Applications, 62: 284-292. http://dx.doi.org/10.1016/j.eswa.2016.06.032

[23] Memon, M.S., Lee, Y.H., Mari, S.I. (2015). Sonia Irshad Mari. Group multi-criteria supplier selection using combined grey systems theory and uncertainty theory. Expert Systems with Applications, 42(21): 7951-7959. http://dx.doi.org/10.1016/j.eswa.2015.06.018

[24] Khan, A.A., Shameem, M., Kumar, R.R., Hussain, S., Yan, X.F. (2019). Fuzzy AHP based prioritization and taxonomy of software process improvement success factors in global software development. Applied Soft Computing, 83: 1-24. https://doi.org/10.1016/j.asoc.2019.105648

[25] Rajak, M., Shaw, K. (2019). Evaluation and selection of mobile health (mHealth) applications using AHP and fuzzy TOPSIS. Technology in Society, 59: 1-17. https://doi.org/10.1016/j.techsoc.2019.101186

[26] Durmuşoğlu, Z.D.U. (2018). Assessment of technoentrepreneurship projects by using Analytical Hierarchy Process (AHP). Technology in Society, 54: 41-46. https://doi.org/10.1016/j.techsoc.2018.02.001 